\title{
COVID-19: Virology, Pathogenesis and Potential Therapeutics
}

\author{
Abdelmonem Awad Hegazy ${ }^{1,2}$, Raafat Awad Hegazy ${ }^{3,4}$ \\ ${ }^{1}$ Professor of Anatomy and Embryology, Faculty of Medicine, Zagazig University, \\ Egypt \\ ${ }^{2}$ College of Biotechnology, Misr University for Science and Technology (MUST), Egypt \\ ${ }^{3}$ Professor of Pathology and Cytology, Faculty of Medicine, Zagazig University, Egypt \\ ${ }^{4}$ College of Medicine, Mutah University, Jordan.
}

Corresponding Author Abdelmonem Awad Hegazy

Mobile:

00201110504321

E mail:

dr.abdelmonemhegazy

@yahoo.com

ahegazy@zu.edu.eg

Key words:

Coronavirus,

Epidemic, Therapeutic,

Outbreak, Healthcare
Nowadays, the coronavirus epidemic represents a major threat to the human being, represented by great numbers of deaths and wide world life disrupt. COVID-19 virus, is not only representing a threat to the life of human being, but also to the economic activities that nearly stopped in many countries due to the partial to complete closure of life activities in order to control the wide spread of virus infections. In these extraordinary and unprecedented critical times of human being life, it is essential to review and discus the virus epidemic in trial to suggest an idea that might be beneficial to researchers to find out an

\section{INTRODUCTION}

An outbreak of infectious disease caused by a novel form of coronavirus has been recognized for the first time in December 2019. Therefore, it is called Coronavirus Disease 2019 (or COVID-19). It has been reported firstly in Wuhan city, in Central Area of China. Then, it widely spread all over the world, nearly involving all countries. The WHO announced it as a pandemic in March 2020 [1]. The virus infection is transmitted from one person to another mainly through droplet transmission via coughing or sneezing. Infection also might be transmitted from pregnant mother to her child [2]. The fatality includes all ages but more affecting old ages with low immunities and patients with other diseases such as respiratory or cardiac disorders.

On the other hand, the previously outbreak known as severe acute respiratory syndrome (SARS) accounted at 2002 to 2003 also started exit from this dark tunnel and to prevent as possible epidemic recurrence. Many attempts of management protocols and trials all over the world, nearly failed until now to control the wide spread and the high incidence of morbidity and mortality of this viral infection. In this review, we highlight the virology and pathogenesis of epidemic and possible used therapeutics in a simplified and concise form to be easily understood and available for healthcare members and even general population. This might help in control and eradication of the current epidemic.

Guangdong Province, China. The causative virus, SARS-CoV also belongs to coronavirus family [3]. The WHO early warned the world in 2003 about an unexpected severe respiratory illness spreading out in Vietnam, Hanoi and Hong Kong. Then, SARS was reported from 32 countries with more than 900 deaths. It was stated that SARS is less infectious than normal influenzas; most infections occur in persons in close contact with patients including healthcare workers. Most cases of mortality were occurring in old ages above 65 years [4]. Identification of the genome of the virus could help in its combating whether through an identification of rapid method for its diagnosis or finding a therapeutic and immunization [5].

The current review aims to clarify the nature of the virus and the available trials in therapeutics. 


\section{METHODS}

The previous literature was searched at Google Scholar, PubMed, Web of Science, Research Gate, WHO websites and others scientific data bases. We reviewed and discussed the most recent papers regarding COVD-19 as well as SARS viruses' outbreaks; in particular type of viruses and possible therapeutics.

\section{RESULTS and DISCUSSION}

\section{Virology:}

The novel strain of coronaviruses (CoVs) causing COVID-19 is termed SARS-CoV-2 to distinguish it from the SARS-CoV (Severe Acute Respiratory Syndrome Coronavirus) that previously reported to cause SARS outbreak in 2003, and genetically related to it [6].

Coronaviruses belong to family of Coronaviridae; representing its sole genus. The virus is composed of a single enveloped pleomorphic strand of RNA. Its size varies from 26 to 32 kilobases; and diameter of about 120$160 \mathrm{~nm}$, representing the largest of the known RNA viruses [7]. It appears in electron micrograph as crown-like structure so it derives its name "corona". Its surface is characterized by spikes-shaped projections (Fig. 1). These projections are composed of a high molecular weight glycoprotein (Spike or S proteins); and show specific antigens that easily removed by protease enzyme. The $\mathrm{S}$ proteins are the most variable genome sequence of the virus; and used for host receptor binding and hence entry of the virus $[4,7]$. The envelope surrounding the RNA virus strand might protect it; allowing it to survive for some times in the air of the patients' environment as well as on the surfaces.

Presence of the envelope surrounding the viruses including human coronavirus keep the infections possible on the surfaces for several days [8]. The virus could be affected by the surrounding media including heat and moisture. Drying and increase of heat might have a reducing impact on the survival of viruses [9]. Therefore, the infections might be decreased in summer where the environment temperature increases.

The coronaviruses include three groups; each has an animal host [4]. Accordingly, COVID-19 also has been suggested of animal origin. This is because virus has the same homology with that isolated from civet cats [3]. SARS coronavirus
(SARS-CoV) is also not documented to circulate in humans before its first outbreak; it has a zoonotic origin [4]. The virus causing COVID19 is identical to SARS-CoV, and more closely related to other bat coronaviruses [5]. It in general propagates in same cells similar to that needed for growing of SARS-CoV; but flourishes better in epithelium of the human respiratory airways [10].

SARS-CoV transmission doesn't occur from asymptomatic or less infected persons with mild signs except after inhabitation of the lower respiratory and intrapulmonary air-ways. This in contrary to SARS-CoV-2 which has error in error-prone RNA-dependent RNA polymerases that enables it for mutation and re-combination [5]. These mutations and re-combinations facilitate virus entering into the host cells through affecting its spike proteins. Such processes might affect controlling the virus; and make it a constant threat to the human being [11].

Infection is shown to be acquired by transmission through the mucous membranes in particular of the nose, mouth and eye conjunctiva. Transmission occurs either by direct exposure or contact with patients or indirectly through touch or use of towels, fomites or surfaces used by patients. Respiratory transmission occurs through exposure to droplets of variable sizes aired from patients for a distance up to 1-1.5 meters. Airborne viruses in small droplet particles (less than $5 \mu \mathrm{m}$ in diameter) might remain for a long time in immediate environment of patients and infect other persons. Indirect transmission might occur through handling the contaminated objects then touch the nose, mouth or eyes [12].

The disease takes a relatively short incubation period of average 4-6 days might extend to 14 days in a small proportion of population; but a long period of clinical presentation might occur reaching many weeks to end by cure or even death. The clinical manifestations were mostly including fever, cough and body aches. There may be headache, sore throat, diarrhea, hemoptysis and/or sputum expectoration in some patients. The cases also develop dyspnea and respiratory difficulties within about one week from the start of symptoms of illness. Pneumonia occurs in all patients with acute respiratory distress in some cases. The complications 
include acute cardiac injury, shock and acute renal failure [13].

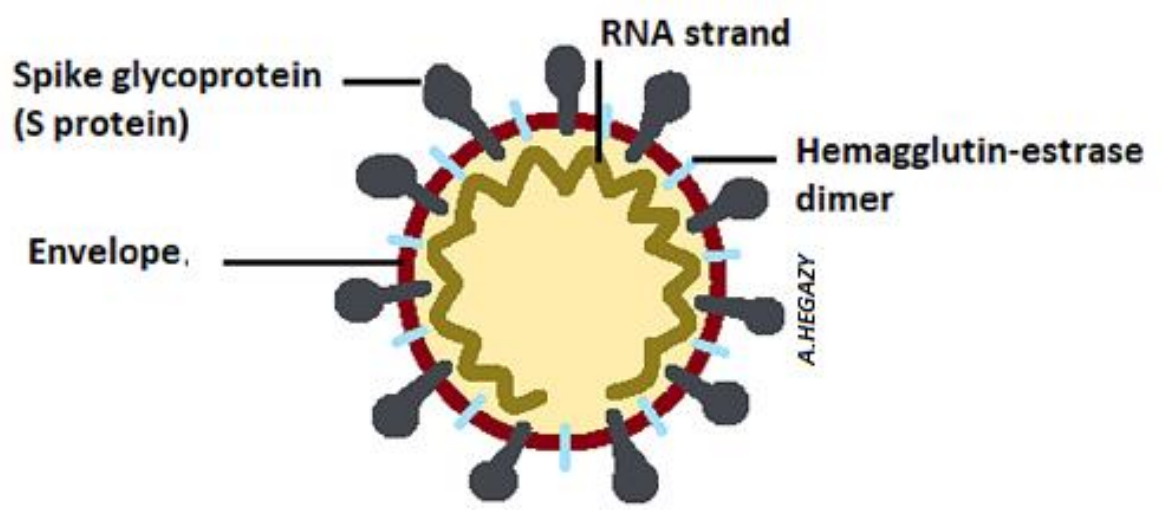

Figure (1): Diagram showing structure of SARS-CoV-2.

\section{Pathogenesis:}

As we mentioned before, COVID-19 virus is a single stranded RNA with a reverse transcriptase enzyme formed of two polyproteins ppla and pplab comprising 16 non-structural proteins [14]. The virus binds to epithelial cells of upper airway, through the receptor angiotensin convertase enzyme 2 (ACE2) [15]. Then, the virus gains double membranes from rough endoplasmic reticulum (RER) of the host cell. The viral nonstructural proteins rearrange the gained membranes to form vesicles of virus in which its replication and transcription take place [14]. The virus replicates inside the cells for about one week. In this period, viral tropism to upper airway cells is responsible for viral shedding and high infectivity of patients [16]. Then it either, or both reaches the lower respiratory system and the blood stream. In the lung, it invades type II pneumocytes carrying ACE2 enzyme. The virus replicates within pneumocyte leading to its destruction and consequent loss of production of surfactant that protects the lung from collapse [17].

When COVID-19 reaches the blood stream, it invades B-lymphocytes, T-lymphocytes, and also natural killer (NK) cells, evidenced by their marked decrease in patients. Mechanism of destruction of such cells induced by the virus is still unclear [18]. However, it has been found a decrease in CD4+ T-cells, but relatively increase in CD8+ T-cells. We suggest that destruction of these lymphocytes might evoke stormy response of the immune system of the body. This could be represented by a gush of cytokines including interleukin-6 (IL-6), inflammatory markers such as C-reactive protein (CRP) and increase production of fibrinogen with hypercoagulability of the blood. Such hypercoagulability might induce multiple thrombi elsewhere in the body including lungs and coronaries with potential morbidity. The storm of cytokines, in addition to low immunity caused by decrease of lymphocytes and NK cells may be responsible for severe pneumonia. We suggest that extensive inflammatory responses, in addition to destruction of type II pneumocytes, are responsible for acute respiratory distress syndrome (ARDS) that previously stated as a serious complication for COVID-19 [19].

Several factors might contribute to the coagulation disorder in COVID-19 patients. The persistent inflammatory process in severe COVID-19 cases acts as a crucial trigger for coagulation cascade. Increased cytokines like IL6 could activate the coagulation and suppress the fibrinolytic system. Moreover, pulmonary and peripheral endothelial cell injury occurring by direct viral attack could be another trigger for coagulation. Such dysfunctional coagulation also could more potentiate the aggressive immune reaction [16].

Hypercoagulability signed by prolonged prothrombin time, elevated levels of D-dimer and fibrinogen, and near normal activated partial thromboplastin time) could lead to disseminated intravascular coagulation (DIC) and multiple blood thrombi [20,21]. The thrombi in lungs worsen ARDS, and in the coronaries might lead to sudden death that occurs in some cases.

Some authors noticed at autopsies of COVID-19 cases a presence of deep venous thrombosis in some cases with no past medical history of its possibility [22]. Also, they found extensive alveolar damage and presence of SARS-CoV-2 
in high concentration in the lung tissues and in blood after postmortem investigation of bodies of some cases.

COVID-19 also might invade ACE2-carrying cells found in vascular endothelium, respiratory epithelium, alveolar monocytes, renal tubular cells and macrophages [23]. Therefore, COVID19 may be responsible for multi-organ failure. Functional research aiming blockade of ACE2 protein that represents the route receptor for entry of virus into human body is highly recommended.

\section{Therapeutics:}

There are great challenges to find out therapeutic for the existing disaster of coronavirus epidemic. This might be due to its mutations; however, there are some light seen in the research community regarding specific treatment.

Due to similarity of the genome between SARS and COVID-19 viruses, some scientists have advised re-use of therapeutic given previously for combating SARS in this current epidemic of coronaviruses. These drugs included use of ribavirin as well as glucocorticoids [24]. The WHO has not recommended the use of glucocorticoids for treatment of cases of COVID-19 unless they are associated with exacerbating obstructive airways [1].

Ribavirin is a nucleoside analog having broad antiviral effects against both DNA and some RNA viruses. It has been used for treatment of hepatitis; and showed improvement of symptoms without affecting virus load [25]. It is given for treatment of hepatitis $\mathrm{C}$ virus (HCV) combined with interferon. The HCV is of the RNA type of viruses like coronaviruses. It could be administered orally or by aerosol [4]. Moreover, pre-clinical use in-vitro proved effectiveness against COVID-19 [26]. These factors in addition to its availability and low cost put the ribavirin as a potential therapy for cure of COVID-19. However, its use still needs further clinical investigations [27].

Lopinavir and ritonavir which are protease inhibitors were also used for management of cases of SARS in 2003. They were noticed to exhibit some better outcome in SARS patients [28]. However, trials to use these drugs in treatment of COVID-19 showed no better results beyond the standard measures [27]. However, the authors recommended further investigations to clarify its benefits in protocol of management in the future.

Remdesivir (GS-5734) that is nucleoside analog and previously used for treatment of Ebola virus has been also investigated against SARS with some benefits. Moreover, preclinical study showed great significance against coronaviruses $[1,29]$. Therefore, GS-5734 has been suggested for management of patients of COVID-19. In this respect, clinical trial showed some benefits for the patients [26].

On the other hand, chloroquine 'antimalarial' has been found to be of some significance in treatment of patients with emerging COVID-19. Hydroxychloroquine 'analogue of chloroquine' is also an antimalarial drug but used mainly for autoimmune disorders such as rheumatoid arthritis and lupus [30]. Both chloroquine and hydroxychloroquine could inhibit in-vitro SARS viruses [31]. It also has been tested for treatment of $\mathrm{HCV}$ indicating modest effect [32]. Azithromycin like chloroquine is also suggested to have a potential role in management of emerging COVID-19. However, the two drugs need further investigations to confirm their efficiency [33].

Based on the postmortem findings as well as the possibility of occurrence of hypercoagulability, some authors recommend prophylactic thromboembolic therapeutic measures [34]. The low molecular weight heparin (LMWH) and anticoagulants have been used as a prophylactic therapy for patients with COVID-19 [35]. Full medication protocol of anticoagulants is indicated for severe cases; and was noticed to be associated with reduced mortality rate [20].

Convalescent plasma $(\mathrm{CP})$ has been tried to control the COVID-19 infections. It has been shown to have a promising role in neutralization of viremia and improvement of clinical outcome, but also it needs further studies to establish protocol of management [36]. However, the frequent mutation of this strain of viruses make the treatment with $\mathrm{CP}$ and even immunization to prevent its occurrence in the future more or less difficult.

No medication has been so far shown to effectively lessen the mortality from this epidemic in all published researches. All such medications are still under testing and not yet totally approved. All measures taken from the health authorities of the different countries have 
been focused on reducing the risk of infection through physical distancing between individuals in addition to adoption of self-protection such as wearing face-masks and strict washing of hands before touch of face, nose, eyes and mouth. Moreover, detection of cases and their isolation with symptomatic and supportive medications, follow-up of contacts and quarantines' measures have been taken [37].

\section{CONCLUSION}

COVID-19 is a major health challenge threatening the life of humans all over the world. It is caused by infection with a novel subtype of RNA viruses "SARS-CoV-2" belonging to coronaviruses. The virus has an envelope that enables it to survive and infect more cases. It also has the ability of frequent mutations so its control through drugs and immunization needs further researches and might take a long time. Many drugs and attempts have been tested, including drugs used before for management of viruses particularly SARS and HCV as well as convalescent plasma, but there is no consensus regarding the management and control of the current epidemic up till now. Until achievement of such progress, universal precautions for avoiding infections transmissions should be taken into consideration. Control efforts should include all countries and societies at the same time. Physical distancing of individual from others is essential to break the closed circle of infection spread. Every one may know that selfprotection is a very important job for the person and for the whole world. This is essential as survival of viruses for the next winter in any spot of world even with little cases might represent a potential source of new infection outbreaks and more aggressive global challenge.

\section{Acknowledgments}

The work has no funding. The diagram is drawn by the first author.

\section{Conflict of Interest: None}

\section{REFERENCES}

1. Sharma M, Surani S. Searching an Effective Therapy for the Coronavirus Pandemic: Do We See Light at the End of the Tunnel? Cureus 2020 Mar 25; 12(3):e7415. doi: 10.7759/cureus.7415
2. Rothan HA, Byrareddy SN. The epidemiology and pathogenesis of coronavirus disease (COVID-19) outbreak. J Autoimmun 2020 May; 109:102433. doi: 10.1016/j.jaut.2020.102433.

3. Guan Y, Zheng BJ, He YQ, Liu XL, Zhuang $\mathrm{ZX}$, Cheung CL, et al. Isolation and characterization of viruses related to the SARS coronavirus from animals in southern China. Science 2003 Oct 10; 302(5643):276-8. doi: 10.1126/science.1087139.

4. Bannister B, Gillespie S, Jones J. Infection: Microbiology and Management. Blackwell Publishing Ltd, 2006.

5. Zhu N, Zhang D, Wang W, Li X, Yang B, Song $\mathrm{J}$, et al. A novel coronavirus from patients with pneumonia in China, 2019. N Engl J Med 2020 Feb 20; 382(8):727-733. doi: 10.1056/NEJMoa 2001017.

6. Pal M, Berhanu G, Desalegn C, Kandi V. Severe Acute Respiratory Syndrome Coronavirus-2 (SARS-CoV-2): An Update. Cureus 2020 Mar 26;12(3):e7423. doi: 10.7759/cureus.

7. Woo PC, Huang Y, Lau SK, Yuen KY. Coronavirus genomics and bioinformatics analysis. Viruses 2010 Aug; 2(8):1804-20. doi: 10.3390/v2081803.

8. Geller C, Varbanov M, Duval RE. Human coronaviruses: insights into environmental resistance and its influence on the development of new antiseptic strategies. Viruses 2012 Nov 12;4(11):3044-68. doi: 10.3390/v4113044.

9. Brady MT, Evans J, Cuartas J. Survival and disinfection of parainfluenza viruses on environmental surfaces. Am J Infect Control 1990 ; 18:18-23. doi: 10.1016/01966553(90)90206-8.

10. Perlman S. Another Decade, Another Coronavirus. $N$ Engl J Med 2020 Feb 20;382(8):760-762. doi: 10.1056/NEJMe 2001126

11. Li F. Structure, function, and evolution of coronavirus spike proteins. Annu Rev Virol 2016 Sep 29;3(1):237-261. doi: 10.1146/ annurev-virology-110615-042301.

12. WHO Scientific brief; Modes of transmission of virus causing COVID-19: implications for IPC precaution recommendations. (2020). Accessed: 5-5-2020: $\quad$ https://www.who.int/newsroom/commentaries/detail/modes-oftransmission-of-virus-causing-covid-19implications-for-ip. 
13. Bi Q, Wu Y, Mei S, Ye C, Zou X, Zhang Z, et al. Epidemiology and transmission of COVID19 in 391 cases and 1286 of their close contacts in Shenzhen, China: a retrospective cohort study. Lancet Infect Dis 2020 Apr 27;S14733099(20)30287-5. doi: 10.1016/S14733099(20)30287-5.

14. Li X, Geng $\mathrm{M}$, Peng $\mathrm{Y}$, Meng $\mathrm{L}, \mathrm{Lu} \mathrm{M}$. Molecular immune pathogenesis and diagnosis of COVID-19. J Pharm Anal 2020 Apr; 10(2):102-108. doi: 10.1016/j.jpha.2020.03.001.

15. Zhou $\mathrm{P}$, Yang $\mathrm{X}$, Wang $\mathrm{X}$, Hu B, Zhang L, Zhang W, et al. A pneumonia outbreak associated with a new coronavirus of probable bat origin. Nature 2020; 579: 270-273. https://doi.org/10.1038/s41586-020-2012-7

16. Cao W, Li T. COVID-19: towards understanding of pathogenesis. Cell Res 2020; 28:1-3. doi: 10.1038/s41422-020-0327-4.

17. Mason RJ. Pathogenesis of COVID-19 from a cell biology perspective. Eur Respir J 2020; 55(4):2000607. doi:10.1183/13993003.006072020.

18. Qin C, Zhou L, Hu Z, Zhang S, Yang S, Tao Y, et al. Dysregulation of immune response in patients with COVID-19 in Wuhan, China. Clinical Infectious Diseases 2020. doi:10.1093/cid/ciaa248

19. Gibson PG, Qin L, Puah S. COVID-19 ARDS: clinical features and differences to "usual" preCOVID ARDS. Med J Aust 2020; Available at: https://www.mja.com.au/journal/2020/covid-19ards-clinical-features-and-differences-usual-precovid-ards

20. Panigada M, Bottino N, Tagliabue P, Grasselli $\mathrm{G}$, Novembrino $\mathrm{C}$, Chantarangkul $\mathrm{V}$, et al. Hypercoagulability of COVID-19 patients in Intensive Care Unit. A Report of Thromboelastography Findings and other Parameters of Hemostasis. J Thromb Haemost 2020 Apr 17. doi: 10.1111/jth.14850.

21. Tang N, Li D, Wang X, Sun Z. Abnormal coagulation parameters are associated with poor prognosis in patients with novel coronavirus pneumonia. J Thromb Haemost 2020; doi: 10.1111/jth.14768.

22. Wichmann D, Sperhake JP, Lütgehetmann M, Steurer S, Edler C, Heinemann A, et al. Autopsy Findings and Venous Thromboembolism in Patients With COVID-19. Ann Intern Med 2020 May 6: M20-2003. doi: 10.7326/M20-2003.
23. Li SR, Tang ZJ, Li ZH, Liu X. Searching therapeutic strategy of new coronavirus pneumonia from angiotensin-converting enzyme 2: the target of COVID-19 and SARS-CoV. Eur $J$ Clin Microbiol Infect Dis 2020 Jun; 39(6):1021-1026. doi: 10.1007/s10096-02003883-y.

24. Chiou HE, Liu CL, Buttrey MJ, Kuo H, Liu H, Kuo $\mathrm{H}$, et al. Adverse effects of ribavirin and outcome in severe acute respiratory syndrome. Experience in two medical centers. Chest 2005 Jul; 128(1):263-72. doi: 10.1378/chest.128.1.263

25. Hultgren C, Milich DR, Weiland O, Sällberg M. The antiviral compound ribavirin modulates the $\mathrm{T}$ helper (Th) 1/Th2 subset balance in hepatitis B and $\mathrm{C}$ virus-specific immune responses. J Gen Virol 1998 Oct;79 ( Pt 10):2381-91. doi: 10.1099/0022-1317-79-10-2381.

26. Wang M, Cao R, Zhang L, Yang X, Liu J, Xu $\mathrm{M}$, et al. Remdesivir and chloroquine effectively inhibit the recently emerged novel coronavirus (2019-nCoV) in vitro. Cell Res 2020 Mar;30(3):269-271. doi: 10.1038/s41422-0200282-0.

27. Chu CM, Cheng VCC, Hung IFN, Wong MML, Chan KH, Chan KS, et al. Role of lopinavir/ritonavir in the treatment of SARS: initial virological and clinical findings. Thorax 2004 Mar; 59(3):252-6. doi: 10.1136/thorax.2003.012658.

28. Cao B, Wang Y, Wen D, Liu W, Wang J, Fan G, et al. A Trial of Lopinavir-Ritonavir in Adults Hospitalized with Severe Covid-19. N Engl J Med 2020 May 7; 382(19):1787-1799. doi: 10.1056/NEJMoa2001282.

29. Sheahan TP, Sims AC, Graham RL, Menachery VD, Gralinski LE, Case JB, et al. Broadspectrum antiviral GS-5734 inhibits both epidemic and zoonotic coronaviruses. Sci Transl Med 2017 Jun 28; 9(396):eaal3653. doi: 10.1126/scitranslmed.aal3653.

30. Touret F, de Lamballerie X. Of chloroquine and COVID-19. Antiviral Research 2020; 177:10.1016/j.antiviral.2020.104762

31. Keyaerts E, Vijgen L, Maes P, Neyts J, Van Ranst M. In vitro inhibition of severe acute respiratory syndrome coronavirus by chloroquine. Biochem Biophys Res Commun 2004 Oct 8; 323(1):264-8. doi: 10.1016/j.bbrc.2004.08.085. 
32. Helal GK, Gad MA, Abd-Ellah MF, Eid MS. Hydroxychloroquine augments early virological response to pegylated interferon plus ribavirin in genotype-4 chronic hepatitis C patients. J Med Virol 2016 Dec; 88(12): 2170-2178. doi: 10.1002/jmv.24575

33. Choudhary R, Sharma AK, Choudhary R. Potential use of Hydroxychloroquine, Ivermectin and Azithromycin drugs in fighting COVID-19: trends, scope and relevance. New Microbes New Infect 2020 Apr 22; 35:100684. doi: 10.1016/j.nmni.2020.100684.

34. Kollias A, Kyriakoulis KG, Dimakakos E, Poulakou G, Stergiou GS, Syrigos K. Thromboembolic risk and anticoagulant therapy in COVID-19 patients: Emerging evidence and call for action. Br J Haematol 2020 Apr 18. doi: 10.1111/bjh.16727.
35. Thachil J, Tang N, Gando S, Falanga A, Cattaneo M, Levi M, et al. ISTH interim guidance on recognition and management of coagulopathy in COVID-19. J Thromb Haemost 2020; 18:1023-1026. doi:10.1111/jth.14810

36. Duan K, Liu B, Li C, Zhang H, Yu T, Qu J, et al. Effectiveness of convalescent plasma therapy in severe COVID-19 patients. Proc Natl Acad Sci USA 2020 Apr 28;117(17):9490-9496. doi: 10.1073/pnas.2004168117

37. Adhikari SP, Meng S, Wu J, Mao Y, Ye R, Wang Q, et al. Epidemiology, causes, clinical manifestation and diagnosis, prevention and control of coronavirus disease (COVID-19) during the early outbreak period: a scoping review. Infect Dis Poverty 2020 Mar 17; 9(1):29. doi: 10.1186/s40249-020-00646-x. 